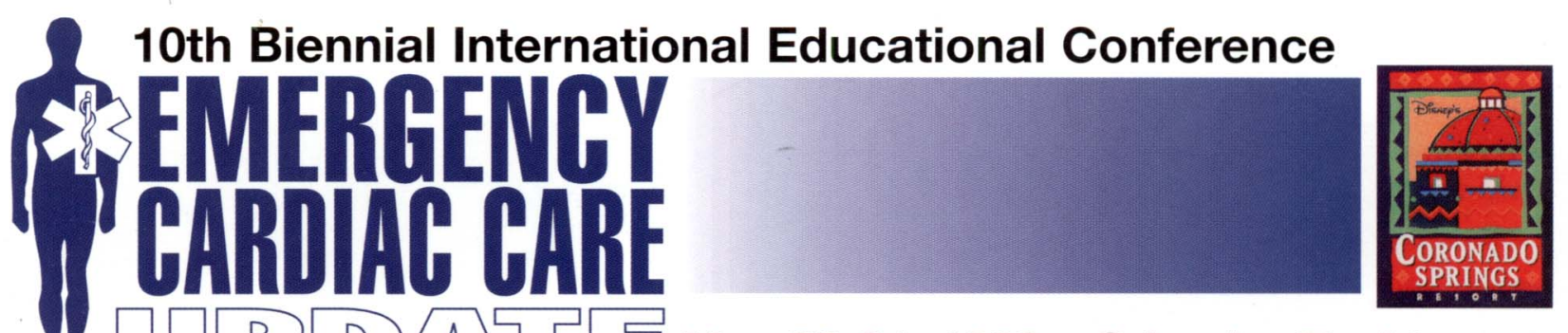

$1 \square \square D C D \square$ May 28-31, 1998 • Orlando, Florida

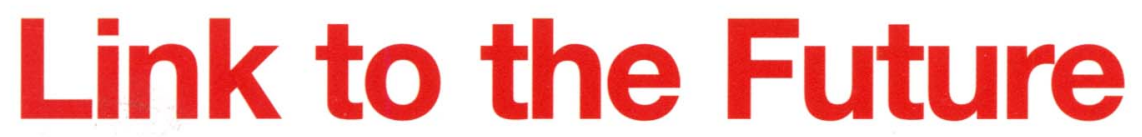

\title{
CALL FOR PRESENTATIONS
}

The Emergency Cardiac Care Update conference in 1998 will focus on guidelines for CPR and ECC. Individuals who would like to share ideas, innovations and trends in a concurrent session, scientific abstract or poster session are invited to participate in ECCU '98.

Topics for presentation include the Chain of Survival (early access, early CPR, early defibrillation, early advanced life support) in conjunction with six categories of emphasis: science, public education, professional education, legislation, program implementation and ethics.

The deadline for submissions is July 15, 1997.

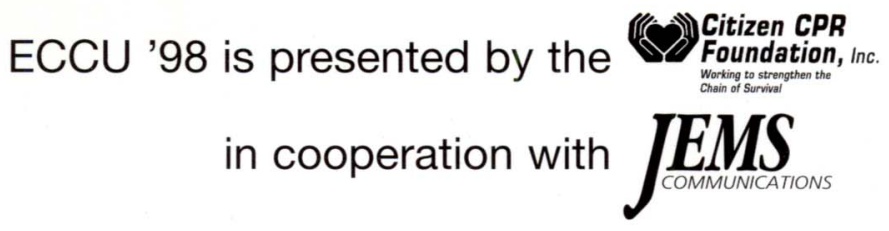

ECCU '98 is sponsored by American Heart Association-National Center, American Heart Association-Florida Affiliate, American Red Cross, and Heart and Stroke Foundation of Canada.

\section{Call for Presentations}

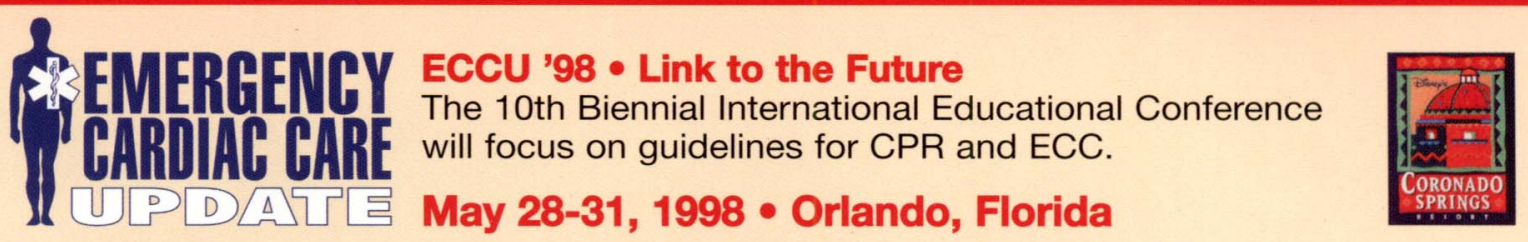

$\square$ YES\& Please send me a Call for Presentations Submissions Packet.

Name Title

Organization

Address

City State

Zip

Telephone (__ _ ____ Fax (

The above is my: $\square$ Work $\square$ Home Address

$x($

PHONE FAX

(800) 266-5367
(760) 431-8135
MAIL

Jems Communications

P.O. Box 2789

Carlsbad, CA 92018 


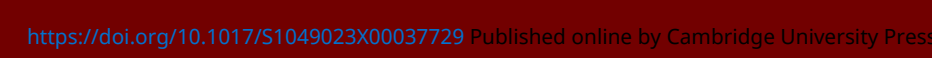

